Jonas Grethlein

\title{
Ornamental and formulaic patterns: The semantic significance of form in early Greek vase-painting and Homeric epic*
}

\section{From ornament to the ornamental}

Ancient vase-painting makes it hard to sustain the dichotomy between ornament and figure, deeply ingrained as it is in our minds. ${ }^{1}$ In a long essay from 1968, Nikolaus Himmelmann makes a strong case for the figurative dimension of the ornament in Greek vase-painting: 'Contrary to some modern epochs, in Greek art the ornamental, seemingly abstract form is not deprived of its figurative significance'. ${ }^{2}$ Flowery ornaments, for instance, are not merely decorative, but still signify vegetation. ${ }^{3}$ While Himmelmann concentrates on Geometric and Orientalising vase-painting, Jeffrey Hurwit observes that, after the separation of image from floral ornament around 600 BC, Archaic and Classical artists consciously undercut the boundary between the two. ${ }^{4}$ Figures cross into the field of decoration and ornaments are treated as real vegetation. On an amphora in Boston, for instance, we see Dionysus within a cluster of vines populated by satyrs (Fig. 3.1). The branch of ivy held by Dionysus replicates the ivy that decorates the handles of the vase. The distinction between figure and ornament is further blurred by one of the satyrs who touches the lotus-palmette chain framing the top of the panel: 'It is as if he is trying to decide whether it is vegetation, too, or whether he can keep on climbing and so scamper out of the vineyard ... into conventional ornament'. ${ }^{5}$ Commenting on similar transgressions between ornament and figure, Richard Neer argues that Euphronius and the Pioneers knowingly gener-

\footnotetext{
* I wish to thank Nikolaus Dietrich and Michael Squire for their helpful comments and suggestions on an earlier draft of this chapter.

1 For recent attempts to question the dichotomy between ornament and figure in art history, see Beyer and Spies 2012 and the special issue on 'ornement/ornemental' in Perspective 1-2 (2010/2011); cf. the historiographical overview in Squire's introduction to this volume.

2 Himmelmann 1968, 266: 'Im Gegensatz zu mancher modernen Epoche erleidet die ornamentale, scheinbar abstrakte Form im Griechischen im Allgemeinen keinen Verlust an Gegenständlichkeit.' See Haug 2015, 25-29 for a survey of works on ornament in early Greek vase-painting, along with Haug's chapter in this book.

3 Cf. e.g. Kéi's chapter in this volume (with further references to Kéi's work).

4 Hurwit 1992. On the frames of Greek vase-painting, see also the chapters in this volume by Kéi and Neer; cf. also Marconi 2017 and Platt and Squire 2017, esp. 12-21, 60-65 (with further bibliography). 5 Hurwit 1992, 63.
} 
This chapter was published by De Gruyter in the book "Gaze, Vision, and Visuality in Ancient Greek Literature" edited by A. Kampakoglou et al. , 2018. https://www.degruyter.com/view/product/495335

The research for this thapter hbphnescereted Union's Seventh Framework Programme (FP/2007-2013)/ERC Grant Agreement no. 312321 (AncNar).

ate friction between such decorative elements as palmettes and figures rendered with breathtaking mimêsis. ${ }^{6}$

In this chapter, I suggest redirecting the focus from the motif of the ornament to the category of the ornamental. I will follow, and expand on, recent work that views ornaments as the most marked part of a more general ornamental aspect of pictures. Considering this ornamental character will drive home that ornament, far from being opposed to image, is an aspect of representation that is constitutive to images. Moreover, the notion of the ornamental will pave the way for a fresh look at picture and narrative as two modes of representation that are distinct and yet share some common ground. Whereas the comparison across media provides a broad set-up, I shall focus on very early material, namely Archaic Greek vase-painting and Homeric epic. I will juxtapose, more precisely, the ornamental in the former with formulae in the latter to explore the semantic significance of both.

The scholarly interest in the ornamental as a pictorial category can be traced back to Theodor Hetzer and Otto Pächt. Both were concerned with the patterning of the pictorial field and how it relates to the represented space. Whereas Hetzer identified the ornamental as a characteristic feature of German art, which was then adopted by Italian artists in the sixteenth century, Pächter emphasised the role of 'Bildmuster' in Dutch paintings of the fifteenth century. ${ }^{7}$ More recently, Jean-Claude Bonne has conceptualised the ornamental in an investigation of ornaments in mediaeval Celtic art. $^{8}$ While Hetzer opposes the ornamental to the ornament, Bonne considers the ornament as a special form of the ornamental. The ornamental is not a motif, but a 'modus operandi whose structuring function lends itself to crossing all genres'.? Bonne provides the following definition: ${ }^{10}$

There is ornamentation to the extent that the configuration of marks, stripped of all meaning, tends to obey principles of construction that allow the covering, the dividing and the orderly articulation of the field or body of inscription. And this, as well as other objects considered, and their articulations can correspond to those of the ornament (and be reinforced by them), or, on the contrary, clash with them.

6 Neer 2002, 54-65 - and above all Neer's chapter in this book. On the representation of palmettes, see also Jacobsthal 1927, 73-110.

7 Hetzer 1987; Pächt 1933.

8 Bonne 1996. See also Bonne 1997. From the very different perspective of Systemtheorie, the constitutive role of the ornamental has been stressed by Luhmann 1995. For applications of this approach in art history, see e. g. Brüderlin 1994 and Glaser 2002.

9 Bonne 1996, 213: 'modus operandi dont la fonction structurante est susceptible de traverser tous les genres.'

10 Bonne 1996, 216: 'Il y a ornementation dans la mesure où la configuration des marques tend à obéir, dans sa littéralité même, à des principes de construction permettant le recouvrement, la partition ou l'articulation ordonnée du champ ou volume d'inscription. Et ceci, ou autre des objets considérés, puisque leurs articulations peuvent correspondre à celles de l'ornement (et se voir renforcées) par elles) ou bien, au contraire, être en décalage par rapport à elles.' 
This chapter was published by De Gruyter in the book "Gaze, Vision, and Visuality in Ancient Greek Literature" edited by A. Kampakoglou et al. , 2018. https://www.degruyter.com/view/product/495335

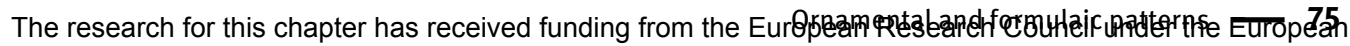
Union's Seventh Framework Programme (FP/2007-2013)/ERC Grant Agreement no. 312321 (AncNar).

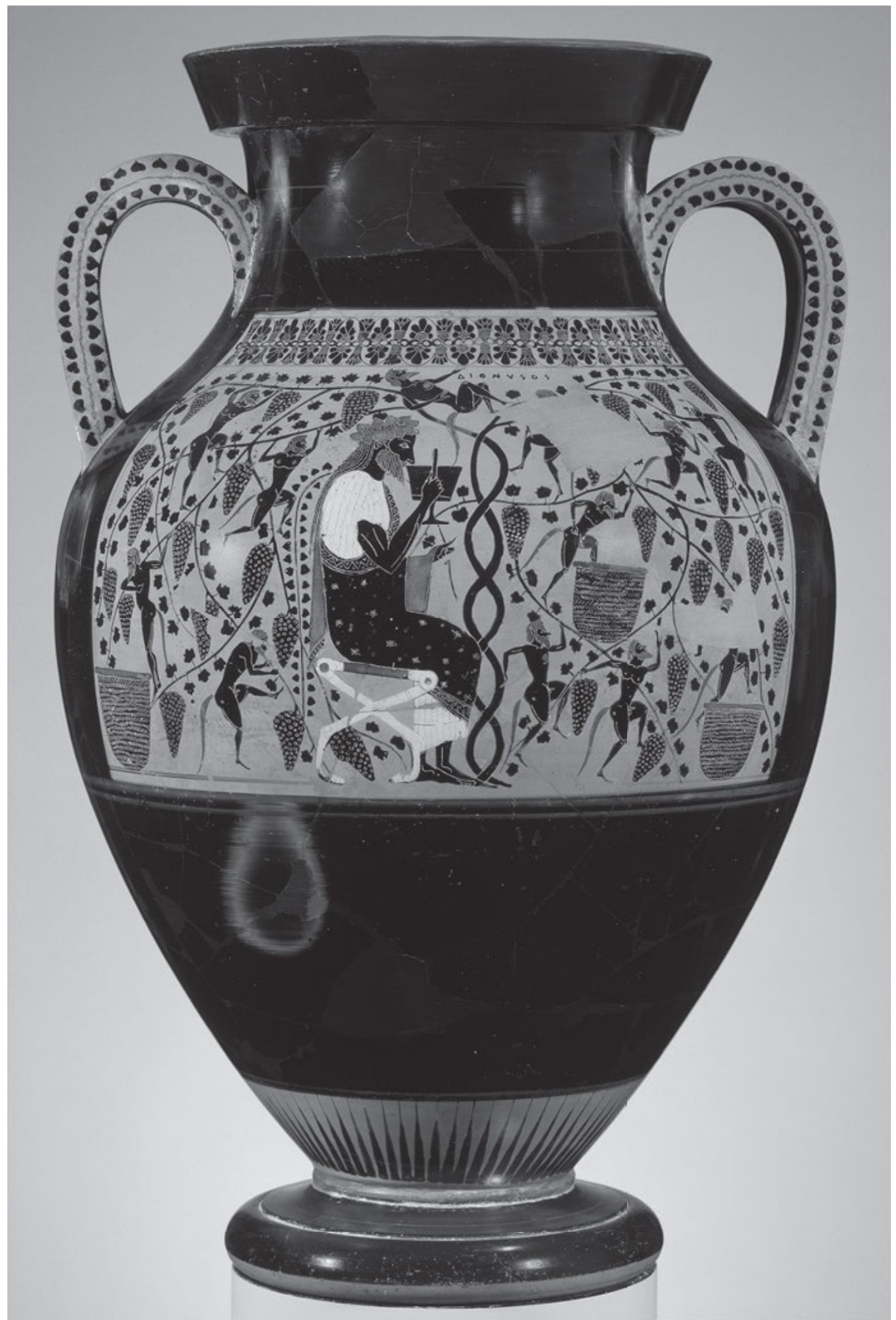

Fig. 3.1: Attic black-figure amphora attributed to the Taleides Painter, showing Dionysus within a cluster of vines populated by satyrs, c. 540-530 BC. Museum of Fine Arts, Boston: inv. 63.952. 
This chapter was published by De Gruyter in the book "Gaze, Vision, and Visuality in Ancient Greek Literature" edited by A. Kampakoglou et al. , 2018. https://www.degruyter.com/view/product/495335

The research for this 6 napter h Union's Seventh Framework Programme (FP/2007-2013)/ERC Grant Agreement no. 312321 (AncNar).

Like other scholars commenting on the ornamental and ornaments, Bonne emphasises the role of repetition. ${ }^{11}$

The notion of iconic difference can help us sharpen the definition of the ornamental. ${ }^{12}$ Pictorial representation combines two levels that are distinct but nonetheless interdependent, the representing medium and the represented object. Marks in the pictorial plane yield figures which appear three-dimensional. Now, as Bonne's focus on 'the covering, the dividing and the orderly articulation of the field or body of inscription' implies, the ornamental belongs to the level of the representing medium. Referring to the pictorial plane and not the represented space, the ornamental concerns patterns no matter what they represent. It can be defined as the repetition of forms and colours independent of their representational value. Seen from this perspective, ornaments crystallise the ornamental quality that any pictorial representation, has, even if in various degrees. In ornaments, the structuring of the pictorial plane that inheres in any pictorial mark outweighs the representation of an object without necessarily negating it.

The ornamental structure of pictures is often described in formalist analysis, which, for example, identifies the triangle form of Mary holding Jesus in Renaissance paintings. The ornamental dimension, however, is not confined to expert analysis; it comes to bear in any response to pictures. This can be explained by the 'twofoldedness' which defines 'seeing-in' according to Richard Wollheim. ${ }^{13}$ As Wollheim notes, when we see something in pictures, we attend simultaneously to the levels of the representing medium and the represented object. The canvas and the colour dots, as well as the scene they represent, are present in our reception. We may concentrate on either, focusing on the movement of the brushstroke or immersing ourselves in the pictorial world, but we nonetheless remain aware of both levels. Through the attention directed to the representing medium, the ornamental dimension that is described in formalist analysis has an impact on any reception of pictures, no matter how learned it is.

The definition of the ornamental in terms of iconic difference and 'seeing-in' also clarifies the reason why a juxtaposition of the ornamental with figure makes little

11 Bonne 1996, 217. For related arguments of the importance of repetition as means of creating figural significance, see Dietrich's chapter in this volume (in the context of Archaic Greek sculpture); cf. also the chapters by e. g. Reinhardt, Elsner, Trimble and Muth (on Roman visual cultural contexts).

12 Classicists and ancient art historians are particularly sensitive to the historical changes that the notion of the picture undergoes. It has become a commonplace to stress the impact of visual cultures on how pictures are viewed. At the same time, it would be difficult to deny a certain degree of continuity across ages and cultures. The notion of iconic difference as well as Wollheim's idea of 'seeing-in' refer to a phenomenological level that, I contend, is transhistorical: see Grethlein 2017c, 177-190. For some illuminating remarks on the phenomenology of pictorial seeing from the perspective of an ancient art historian, see also Neer 2010, 14-19 - along with Neer's chapter in this book (with related discussion of Wollheim).

13 Wollheim 1980; 1987, 43-79. 
This chapter was published by De Gruyter in the book "Gaze, Vision, and Visuality in Ancient Greek Literature" edited by A. Kampakoglou et al. , 2018. https://www.degruyter.com/view/product/495335

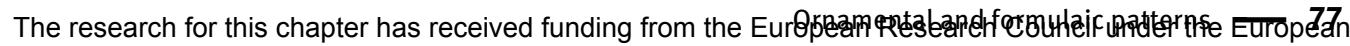
Union's Seventh Framework Programme (FP/2007-2013)/ERC Grant Agreement no. 312321 (AncNar).

sense. Figuration refers to the level of the represented object. It is thus opposed to abstraction, which also describes the representational status of pictorial marks. The ornamental, however, exists on a different level; it inhabits, so to speak, a different plane, as it belongs to the level of the representing medium. The referential status of patterns does not concern its ornamental quality. The shapes of figures as well as the shapes of abstract entities can be ornamental. Conversely, even ornaments, in which the level of the representational medium is dominant, can be figurative.

The ornamental is a category of the representing medium, yet it spills into the level of the represented object. Ornamental features can be semantically significant, not so much through what they represent as through their mere form. Just as represented objects cannot be dissolved from the representing medium, the form of the representation is inextricably bound up with its content. In the first part of the following investigation, I will look at a famous early ('Protoattic') Greek vase, the Eleusis amphora, which illustrates how the ornamental, crossing the boundary between figuration and abstraction, bleeds into the represented scene and its meaning. In the second part, I will then compare this to a parallel in narrative. The repetitiveness of the formulaic language in Homeric epic is, mutatis mutandis, similar to the visual patterns of the ornamental. While primarily a formal feature originating in the oral rhapsodic culture of Archaic Greece, formulaic repetitions have the capacity to generate meaning beyond what they denote. Finally, I will discuss the relation between the ornamental as a transhistorical category and the impact of specific contexts by considering the prominence of the ornamental in vase-painting.

\section{Chasing semantics: The ornamental on the Eleusis amphora}

The Eleusis amphora is an outstanding example of Protoattic vase-painting (Fig. 3.2; cf. also Fig. 8.6). ${ }^{14}$ The intense correspondences between three separate pictures make it a particularly intriguing test-case for the claim that the ornamental can be semantically significant. Dating from the first half of the seventh century BC, it was used as a vessel for the corpse of a boy, who, it seems, was too big to fit through the mouth. So the amphora had to be cut into two pieces and was then, with the corpse in it, put together again. In a thought-provoking article, Robin Osborne has used this function of the amphora as a backdrop for an interpretation of the scenes featured on the front. He argues that the blinding of Polyphemus, a fight between a boar and a lion and

14 On this vase, see besides Mylonas 1957 also Osborne 1988, 1-6; Martens 1992, 258-264; Grethlein 2016, 90-94; Platt and Squire 2017, 17-21. Richard Neer returns to the vase in his chapter in this volume (218-220). 
This chapter was published by De Gruyter in the book "Gaze, Vision, and Visuality in Ancient Greek Literature" edited by A. Kampakoglou et al. , 2018. https://www.degruyter.com/view/product/495335

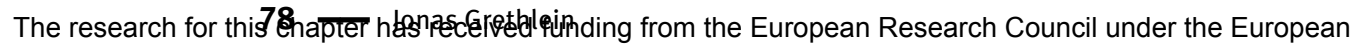
Union's Seventh Framework Programme (FP/2007-2013)/ERC Grant Agreement no. 312321 (AncNar).

the pursuit of Perseus by the Gorgons provide a piercing reflection on death. ${ }^{15}$ Here, I would like to pursue a different path and, while bypassing the context of the vase, take my cue from a formal analysis. As important as context is, form provides another important key that, as we will see, pertains to semantics. I will first elaborate on the ornamental quality of the vase and show how it bleeds into the meaning of the represented scenes.

To start with, the Eleusis amphora lends itself to proving that figure and ornament are not neatly separated in the vase-painting of that period. The borderline between the figurative front and the ornamental back is transgressed by the decapitated body of Medusa, which reaches far into the rough flowery patterns of the back side. ${ }^{16}$ More incisively, on the front side ornaments are not limited to the decorative friezes that are interspersed between the larger figurative friezes. The sparse representation of vegetation is highly stylised and numerous ornaments fill the void between the figures (some of them also covering bodies). Most strikingly, ornament and figure literally converge in the spear that is rammed into Polyphemus' eye - the spear is partly identical with three lines that not only frame the picture of the blinding, but also fully go around the vessel and are therefore ornamental. ${ }^{17}$

It is, however, not the ornaments and how they are entwined with figuration that shall concern us here. Instead I will use the Eleusis amphora as an illustration of the ornamental in the sense sketched above. In Une esthétique de la transgression, Didier Martens elaborated on the recurrence and transformation of patterns across the figurative and ornamental friezes of the Eleusis amphora (Fig. 3.3). His formal analysis, while conducted with a different argumentative purpose, furnishes a useful stepping stone for my exploration of the ornamental. Martens concentrates his analysis on the pattern of the triangle. It appears in the largest ornamental band at the foot of the vase which alternatively features black and white rays, both with the top up. As Martens shows, the pattern is taken up in the first figurative frieze featuring the pursuit of Perseus by the Gorgons. Medusa's lower body consists of a white and a black triangle. While here the triangles are turned 180 degrees, the legs of the two living Gorgons each form an upward-pointing triangle. Athena, in contrast, stands and wears an unfitted robe, so her body does not really shape up to a triangle. The legs of Perseus, though, are triangular again and thus laterally continue the visual echo of the ornamental pattern from the foot of the vase.

15 For a critique of Osborne's interpretation of the Eleusis amphora and its use for social history, see Morris 1993, 28-32; Whitley 1994, 63-65.

16 On the ornamental back that is not clearly demarcated from the picture on the front, see Haug 2015, 175-176.

17 Cf. Hurwit 1977, 24-25, and Morris 1984, 44-45, who also adduce parallels to it. On the interplay between the figurative and the ornamental in the context of other roughly contemporary vase-paintings, also analysed from a formal perspective, see Squire's introduction to this volume (discussing the 'Euphorbus Plate'). 
This chapter was published by De Gruyter in the book "Gaze, Vision, and Visuality in Ancient Greek Literature" edited by A. Kampakoglou et al. , 2018. https://www.degruyter.com/view/product/495335

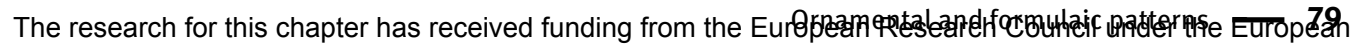
Union's Seventh Framework Programme (FP/2007-2013)/ERC Grant Agreement no. 312321 (AncNar).

The triangular shape can be traced further in the second figurative frieze on the shoulder showing a boar and a lion. The front and hind legs of the boar form two triangles which stand right above the triangles between the legs of the two Gorgons. The back of the lion is not visible anymore, but other comparable depictions make it very likely that their triangular shape would have corresponded to Perseus' legs below. ${ }^{18}$ As the lion raises his left front claw in attack, the space between his front legs opens up - this chimes in well with Athena who figures right underneath. In both cases, the form of the triangle is distorted.

Finally, the neck - with our first iconic attestation of the blinding of Polyphemus: the triangles between the legs of the two comrades of Odysseus correspond with the triangles formed by the front and hind legs of the boar as well as that of the Gorgons and their lower bodies, all along a vertical axis. Like Athena and the front pair of the lion's legs, the first attacker, obviously Odysseus, does not shape up to a triangular form. At the same time, the triangle showing between Polyphemus' lower and upper thighs repeats the form of Perseus' legs as well as, arguably, that of the lion's hind legs.

Now it is nothing special that the legs of figures presented in profile yield a triangle; we can observe this on nearly all vases. On the Eleusis amphora, however, the triangles in the three pictures are closely aligned with each other. Taking up the rays from the bottom, one distorted and three neat lines of triangle create a strong vertical axis that goes through all pictures. The shape of the triangle, cutting across ornament and figure, permeates the entire front of the Eleusis amphora. Set out in an ornamental band, it resurfaces in all three figurative friezes.

Discussions of the ornamental tend to focus on lines and shapes, but it ought not be forgotten that colour is also capable of creating patterns. ${ }^{19}$ Again, the Eleusis amphora is a case in point as colour trenchantly reinforces the ornamental link forged between the three figurative friezes. White colour creates a vertical axis that aligns Odysseus, the lion's head and Athena. This white block is opposed by a black axis which also extends through all three pictures, from Polyphemus via the body of the lion to Perseus, whose body seems to have been black too. Colour thus strengthens the vertical axis established by the triangle and other forms. ${ }^{20}$

\footnotetext{
18 Martens 1992, 263.
}

19 Cf. Roque 2010/2011, 19-20.

20 One qualification needs to be made: on the one hand, the body of Odysseus and at least some of the dress of Athena seem to have been highlighted by added white; on the other, the head of the lion as well as the face of the lion were kept in the less distinct, if light, colour of the clay. While supporting the argument for a black axis reaching from Polyphemus via the body of the lion to Perseus, this observation may seem to lessen the case for a white axis. That being said, the clay colour of the lion's head still stands out sufficiently against the black of its body, and the limitation of the added white to Odysseus and Athena in this axis reinforces the connection between the goddess and her protegé, on which see below. 
This chapter was published by De Gruyter in the book "Gaze, Vision, and Visuality in Ancient Greek Literature" edited by A. Kampakoglou et al. , 2018. https://www.degruyter.com/view/product/495335

The research for this 8 Gapter h Union's Seventh Framework Programme (FP/2007-2013)/ERC Grant Agreement no. 312321 (AncNar).

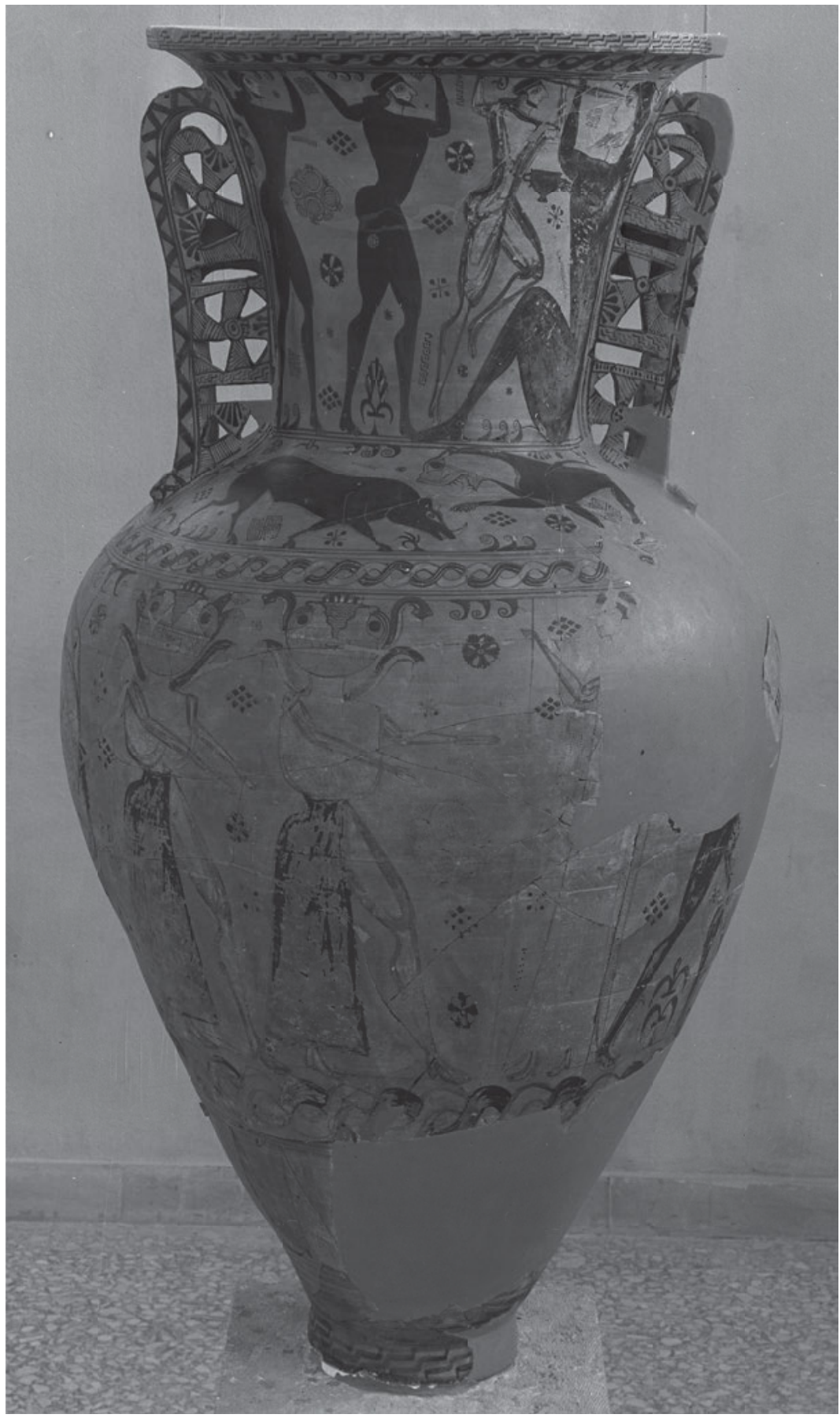

Fig. 3.2: Protoattic black-figure amphora by the Polyphemus Painter, c. 670-660 BC. Eleusis, Archaeological Museum: inv. 2630. 
This chapter was published by De Gruyter in the book "Gaze, Vision, and Visuality in Ancient Greek Literature" edited by A. Kampakoglou et al. , 2018. https://www.degruyter.com/view/product/495335

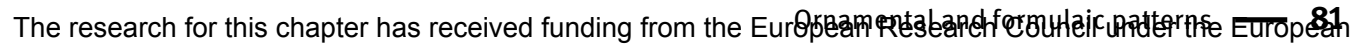
Union's Seventh Framework Programme (FP/2007-2013)/ERC Grant Agreement no. 312321 (AncNar).

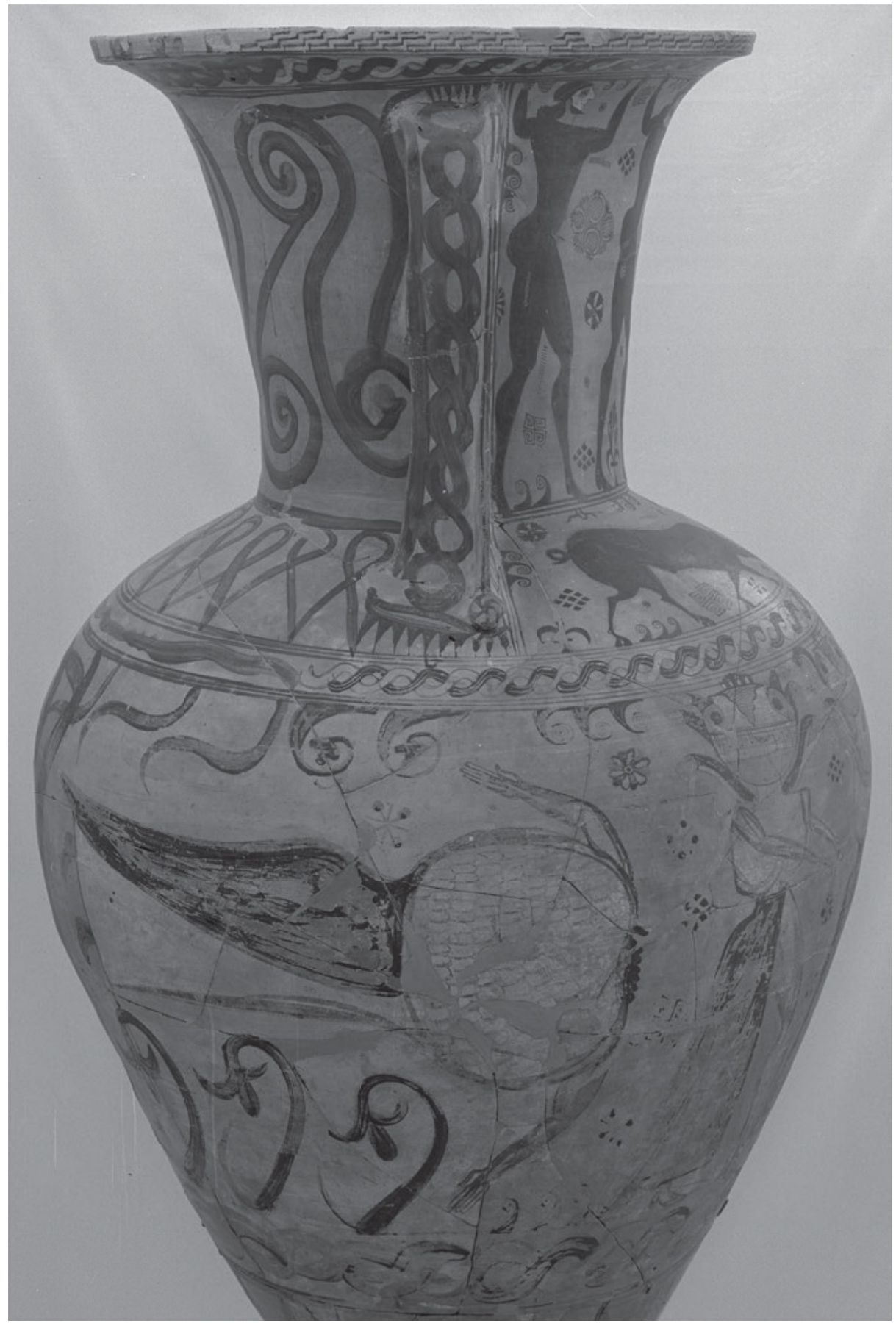

Fig. 3.3: Side-view of the same Eleusis amphora. 
Martens uses his formal analysis of patterns on the Eleusis amphora to prove his idea of an 'animation rhythmique'. He explores patterns as one way in which vases can appear as animated. The transformation of patterns, Martens contends, suggests some kind of agency in the vase which reworks their shapes, in our case the rays that resurface on several friezes of the Eleusis amphora. I would like to take up Martens' formal analysis and deploy it differently. In structuring the pictorial plane, the triangle is a prime example of the ornamental. Of course, the patterning for which I have argued is reinforced through figuration. The reworking of the rays is all the more conspicuous as it is legs that repeat the triangles in the figurative friezes. And yet, the patterning extends to the ornamental friezes and is independent of figuration: it is generated by the repetition of forms and colours no matter what they represent. Besides having representational value, the pictorial marks structure the surface of the vase. Let me now show that this structure, while formal and referring to the medium of representation, nonetheless pertains to the meaning of the represented object.

I start with the two larger pictures, on the belly and the neck, which feature mythological scenes, while the shoulder displays a generic motif. The ornamental structure underscores that both scenes show a single person assaulted by others (Fig. 3.4; cf. Fig. 8.6). The triangles formed by the legs align the forward movements of the aggressors in both pictures. The neat parallel is interrupted by the figure of Athena, which takes the place right under Odysseus. While Polyphemus is assaulted by three men, the third Gorgon has already been decapitated and is relegated to the ornamental back side of the vase. This difference does not detract from the inversion underlined by the ornamental quality of the depictions though: in the upper picture, men attack a monster; in the lower picture, monsters attack a man.

Another pattern that extends across ornamental and figurative friezes reinforces the parallel of the two mythological scenes. Three ornamental friezes show a braiding of two lines, one black, the other white. Like the rays, this is a popular ornamental motive. On the Eleusis amphora, however, the u-like pattern of each line is taken up and reproduced on a larger scale by the snakes which frame the heads of the two living Gorgons. Furthermore, on the neck of the vase, the arms of the two comrades wielding the spear above their heads form a u, mimicking the shape of both ornament and snakes. Only part of Athena's upper body is preserved, but her right arm, lifted up, suffices to suggest that her arms paralleled the posture of Odysseus. The pattern highlights the parallel acts of aggression, one levelled against Polyphemus, the other against Perseus.

The juxtaposition gains poignancy from the fact that vision is central to both scenes. Robin Osborne has already commented on the thematic prominence of vision on the vase, which he interprets as 'a construal of death, a discussion of the nature of death as sensory deprivation', ${ }^{21}$ but more can be said. Besides crossing the gaze of

21 Osborne 1988, 4. 
This chapter was published by De Gruyter in the book "Gaze, Vision, and Visuality in Ancient Greek Literature" edited by A. Kampakoglou et al. , 2018. https://www.degruyter.com/view/product/495335

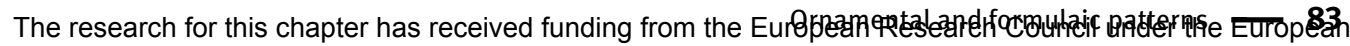
Union's Seventh Framework Programme (FP/2007-2013)/ERC Grant Agreement no. 312321 (AncNar).

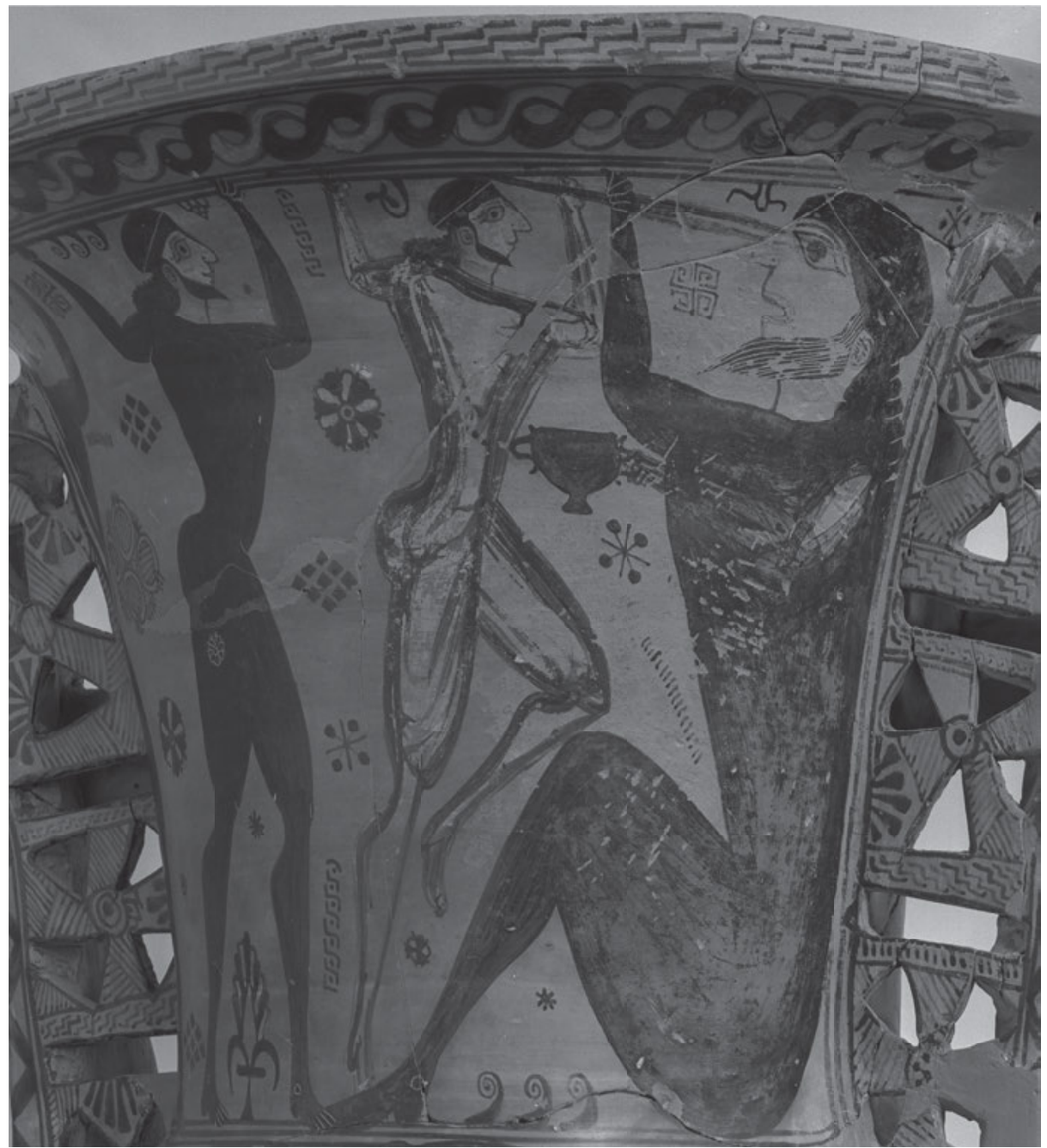

Fig. 3.4: Detail of the Cyclops scene on the neck of the same Eleusis amphora.

the vase's beholder, the petrifying look of the Gorgons contrasts with the blinding of Polyphemus: the former highlights the power of the eye; the latter reveals its vulnerability. ${ }^{22}$ Vision is envisaged as the medium that calibrates the relation between man and monster. While it is the gaze of the Gorgons that threatens Perseus, Odysseus and his men triumph over the Cyclops by depriving him of eyesight.

22 For the full argument, see Grethlein 2016, 90-94 - along with Grethlein 2015, 204-205. On Gorgons and their gaze in vase-painting, see Howe 1954; Vernant 1990, 115-117; Frontisi-Ducroux 1995, 71-74; Mack 2002. For further literature, see Neer 2002, 43, n. 56. 
The research for this $\mathbf{8}$ hapter h Union's Seventh Framework Programme (FP/2007-2013)/ERC Grant Agreement no. 312321 (AncNar).

The ornamental dimension also suggests additional ways of relating the scenes and protagonists to each other. Highlighted by the added white, Odysseus stands in a line with Athena. As I have just pointed out, this alignment makes little sense in the narrative logic of the scenes: Odysseus assaults Polyphemus; Athena assists Perseus. The same white colour that singles out Odysseus as the most prominent attacker ${ }^{23}$ elevates Athena above the scene and possibly marks her as divine. That being said, the iconic linking of Odysseus to Athena abounds in significance beyond the featured scenes. It alerts the spectator to the fact that Odysseus is another protégé of Athena. In the Odyssey, she is his closest ally and plays a crucial role in his nostos. Far from pressing a single interpretation, the formal structuring of the representing surface opens up various avenues to the meaning of the scenes represented.

Located on the vessel's shoulder and sandwiched between two mythological scenes, the generic motif of the boar and lion is clearly not the main focus of the Eleusis amphora. Nonetheless, the ornamental structure, of which the middle scene forms a part, puts the animal fight into a dialogue with the pursuit of Perseus and the blinding of Polyphemus. The triangle pattern as well as the colour underscore that the clash of the two unequal animals parallels the encounters of heroes with monsters. Since the lion covers the space over Athena as well as Perseus, the picture seems to match the scene below more closely than that above, where the same space is inhabited by the opponents Odysseus and Polyphemus. While the white head of the lion continues the colouring of Athena, the black body puts the lion in a line with Perseus. The juxtaposition, however, is not that neat. The hatching covering the lion's muzzle is similar to the patterns on the Gorgons' faces, thus establishing an iconographic link across party lines.

The interaction of the animal scene with the blinding of Polyphemus may be less obvious, but it is thought-provoking if one is willing to bring Homer into play. Of course, Archaic vase-paintings ought not to be approached as illustrations of literary texts. ${ }^{24}$ Picture and text are two different representational media that follow their own logic and can operate independently from each other. This, however, should not prevent us from interpreting pictorial representations against the backdrop of textual accounts. Here, the juxtaposition effected by the ornamental structure provides, to some extent, an iconic analogue to the comparison of heroes with both boars and lions in epic similes. ${ }^{25}$ In the Iliad, Odysseus himself is once compared with a boar (Il. 11.414). The Eleusis amphora suggests the same comparison in that Odysseus and

23 Osborne 1998, 60, suggests a more pronounced interpretation: 'Is this just to make him different, or does it stand for the way Odysseus' threat was not visible to the Cyclops?'

24 See, e. g., Squire 2009, 122-139 (along with Squire's discussion of the 'Euphorbus Plate' in this volume).

25 For a simile that has a boar face a lion, see Il. 16.823-826. On the relation between epic similes and animal friezes, see recently Winkler-Horacek 2015, 312-317. 
This chapter was published by De Gruyter in the book "Gaze, Vision, and Visuality in Ancient Greek Literature" edited by A. Kampakoglou et al. , 2018. https://www.degruyter.com/view/product/495335

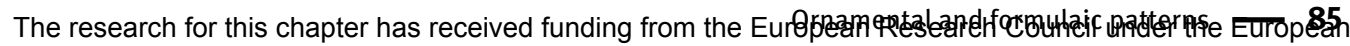
Union's Seventh Framework Programme (FP/2007-2013)/ERC Grant Agreement no. 312321 (AncNar).

his men come from the left like the boar. If we view the picture in the light of the Homeric account, this interpretation is corroborated by the fact that Polyphemus is compared with a 'lion reared in the hills' when he eats a couple of Odysseus' companions, 'without leaving anything, entrails, flesh and marrowy bones alike' (Od. 9.292-293). Seen thus, the animal picture drives home that, like the boar, Odysseus confronts a physically superior opponent.

If, however, the beholder's eye follows the colours, then the contrary assignment is more plausible: light Odysseus to light lion. The pairing with the animal that is likely to win the duel may gesture to Odysseus' final triumph over the Cyclops. More poignantly, like the lion, Odysseus once confronted a boar in the Caledonian hunt (Od. 19.392-466). This is only an association, but one with a famous story and capable of instigating far-reaching questions. A comparison of the blinding of a drunk Cyclops in a cave with the courage of facing a wild boar inevitably makes one ponder on the heroic status of Odysseus. The cunning that allows Odysseus to escape from Polyphemus has little to do with the bravery on show in hunt and combat.

To sum up, the Eleusis amphora shows how the shapes and colours of the pictorial marks yield patterns that, independently of their representational value, structure the surface. ${ }^{26}$ While belonging to the level of the representing medium and not that of the represented scene, this ornamental structure contributes to the meaning of the representation. As I have argued, the ornamental structure puts the three figurative pictures into an intense visual dialogue. It invites close comparisons of Odysseus' encounter with Polyphemus, Perseus' adventure with the Gorgons and a generic duel of two wild animals. The repetition of shapes and colours partly underlines analogies, partly throws into relief differences. What is merely pictorial form thus triggers questions that concern the ambiguity of vision as well as the nature of heroic deeds.

\section{Formulaic diction and meaning in Homer}

I will now pair my analysis of the ornamental on the Eleusis amphora with a reading of a passage from the Odyssey. The comparison of early Greek art with Homeric poetry is a staple in scholarship. It is, one could say, encapsulated in the Iliad itself. As Andrew Sprague Becker and others have shown, the ekphrasis of Achilles' shield sophisticatedly juxtaposes image with text as distinct media of representation. ${ }^{27}$ In modern scholarship, Homeric epic has been compared in particular with Geometric

26 The repetition of patterns across three separate pictures that are in dialogue with each other makes the Eleusis amphora a particularly compelling illustration of my thesis. However, as the inquiry by Martens 1992, 264-283, shows, there are numerous other vases in which ornamental patterns cut across pictures and ornaments, potentially creating new meaning.

27 Becker 1990 and 1995; for discussion of the (inter)medial play, see most recently Squire 2013. 
This chapter was published by De Gruyter in the book "Gaze, Vision, and Visuality in Ancient Greek Literature" edited by A. Kampakoglou et al. , 2018. https://www.degruyter.com/view/product/495335

The research for this $\mathbf{8}$ Gapter h Union's Seventh Framework Programme (FP/2007-2013)/ERC Grant Agreement no. 312321 (AncNar).

art, which advocates of an early date for the Iliad and the Odyssey deem contemporaneous. ${ }^{28}$ The repetitiveness of formulaic diction, it is argued, is reminiscent of the ornamental character of Geometric art: ${ }^{29}$

Homeric formulae are, like the motifs of Geometric vases, basically stiff traditional elements, irreducible building blocks of oral epic. A degree of individual remodeling hardly alters their essential nature or reveals much about the poet's personality any more than do the slight variations observable in the different hands of individual vase painters.

Homeric ring-composition, both at the macro- and micro-levels, seems to be the textual equivalent to the symmetries on the friezes of early Greek pottery. Some scholars have even gone so far as to claim that while the structure of the Iliad can be paired with the patterns of Geometric vases, the less severe arrangement of the Odyssey is in synch with the flowery ornaments of the Orientalising period. ${ }^{30}$

At the same time, it has been noted that the Geometric depictions of such standard scenes as a funeral cortège with unidentified individuals are a far cry from the vivid account of specific scenes in the Iliad (or the Odyssey). ${ }^{31}$ For comparisons that focus on motifs instead of structure, later pottery has proven more fruitful. In a series of articles, Anne Mackay teases out parallels between Homer and black-figured Archaic vase-painting. ${ }^{32}$ Discussing various aspects, notably innovation, symmetry and the significance of individual objects, she argues that iconographic attributes and compositions follow the logic which John Miles Foley has ascribed to formulaic diction. For Foley, noun-epithet combinations and other formulae derive their meaning less from the context in which they are used than from the tradition as a whole. ${ }^{33}$ The phrase 'swift-footed Achilles', for example, evokes the entire epic tradition in which Achilles is referred to according to this formula. For Mackay, the same 'traditional referentiality' applies to vase-painting: the lion-skin may in some depictions help to identify Heracles, but more generally it conjures up the tradition of Heracles as a manly hero who has slain the Nemean lion and braved numerous other adventures. The same argument can be made for full-blown scenes such as the warrior's departure. Here, the strongly conventionalised composition makes the spectator view the motif against the backdrop of the iconographic tradition.

In the eyes of Mackay, the parallel between vase-painting and epic bespeaks an oral culture: 'Orality is not merely a feature peculiar to orally composed "texts", but

28 See e.g. Hampe 1936, 1952; Notopoulos 1957; Whitman 1958; Andreae and Flashar 1977 with more bibliography on 230, n. 23; Lewis 1981.

29 Whitman 1958, 91.

30 Andreae and Flashar 1977. See also Whitman 1958, 100, 285-309.

31 Cf. Notopoulos 1957, 74.

32 Mackay 1993, 1995, 1996, 2002.

33 Foley 1991. 
This chapter was published by De Gruyter in the book "Gaze, Vision, and Visuality in Ancient Greek Literature" edited by A. Kampakoglou et al. , 2018. https://www.degruyter.com/view/product/495335

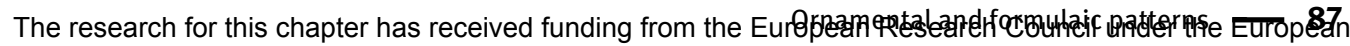
Union's Seventh Framework Programme (FP/2007-2013)/ERC Grant Agreement no. 312321 (AncNar).

is rather a way of thinking, a way of looking at the world. ${ }^{34}$ There is a sort of oral mentality which is predicated on a distinct temporality. Unlike 'our "modern" sense of the linear progression of time', it privileges 'a concept of simultaneity': 'The formulaic phrases and iconographic elements that evoke a supra-contextual or even meta-textual reception on the part of hearer and viewer cannot by their very nature fulfill the modern expectation of a contextually logical, linear narrative progression. ${ }^{35}$

Now while taking up the comparison of textual with pictorial formulae, my own approach comes with a shift of parameters. Whereas Mackay discusses iconographic motifs, the ornamental, the concern of this paper, is constituted by the repetition of forms and colours with no regard for their representational value. Besides moving the focus from the represented object to the medium of representation, I also replace Mackay's diachronic view with a synchronic perspective. Drawing on Foley's notion of 'traditional referentiality', Mackay views depictions against the backdrop of earlier versions of the same motif. In contrast, my analysis targets repetition within a single picture. I would like to show that just as patterns in the pictorial plain bleed into the meaning of the represented object, the repetition of formulae in epic poetry can be semantically charged. For this, I shall cast a quick look at the theory of formulae in Homer, then give an illustrating example from the Odyssey and finally elaborate on the comparison of text with image.

As first spelt out by Milman Parry, Homeric epic, like the songs of guslars that Parry recorded in Serbo-Croatia, consists largely of formulaic diction. ${ }^{36}$ Formulae are ready-made phrases that the bard inherits from tradition. They serve mnemonic functions: only the use of formulae, stabilised through metre, permits the bard to perform such lengthy narratives as the Iliad and Odyssey. The smallest and most striking formulae are noun-epithet combinations, for example 'swift-footed Achilles'. That said, the construction of entire scenes can be formulaic. ${ }^{37}$ The descriptions of such activities as arming, arrival and sacrifice not only draw on formulae, but are themselves highly formalised. They follow a more or less fixed sequence of steps that, depending on the significance of the individual act, can be extended or abbreviated.

Viewing formulae primarily as an aid to versification, Parry and the first generation of his disciples took little interest in their semantic value or even negated it. As Adam Parry notes in the introduction to the edition of his father's papers, Milman Parry 'seemed to believe that the ornamental epithet had virtually no meaning at all: it was a sort of noble or heroic padding'. ${ }^{38}$ This position still echoes in Whitman's above-quoted reference to formulae as 'basically stiff traditional elements'. However,

34 Mackay 1995, 302.

35 Mackay 1993, 110.

36 Parry 1971. For surveys of later theory, see Edwards 1986, 1988.

37 On 'typische Szenen', see already Arend 1933. For a survey, see Edwards 1992.

38 A. Parry in M. Parry 1971, lv, n. 2. 
genesis and meaning are two different aspects of poetry that ought not to be pitted against each other. Formulaic diction can be a technical means of composition and simultaneously carry semantic significance. In fact, oralists after Parry have demonstrated how the repetition of formulae artfully establishes links between individual episodes and thereby contributes to their meaning. ${ }^{39}$ Taking meaning into account has allowed oral analysis to shed some of its sterility.

An example from the same story as the Homeric scene on the Eleusis amphora may illustrate this. Blinded by Odysseus and his comrades, Polyphemus rages, but is unable to catch his opponents. At the same time, Odysseus and his men are still shut in the cave. In order to escape, Odysseus has to come up with another stratagem. He binds his men under sheep and he himself clings to the fleece of the leader of the herd. The next morning, when the herd rushes out to the pasture, Polyphemus feels over the backs of his animals, but 'this, clueless as he was, he did not grasp, that they [i.e. Odysseus and his comrades] had been fastened under the chests of the

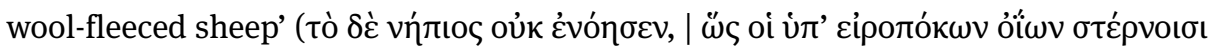

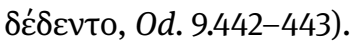

The phrase oúk घ́vón $\sigma \alpha / \varepsilon v / \alpha v$ is a formula that occurs at the end of hexameters in five other passages in the Odyssey. ${ }^{40}$ In one case, the repetition becomes a marked echo as not only the formula, but also the preceding phrase is taken up. At the beginning of Book 22, the suitors are lingering in the megaron without weapons when Odysseus, under the alias of the beggar, commences his bloody revenge with shooting Antinous. The suitors assume that he killed their peer unintentionally, but 'this, clueless as they were, they did not grasp, that for all of them the ropes of their demise

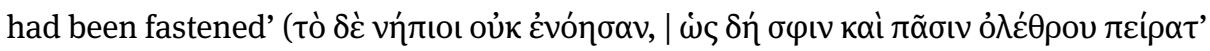
$\dot{\varepsilon} \varphi \tilde{\eta} \pi \tau 0,22.32-33)$. The re-use of the half-line from Book 9 is further highlighted by the subsequent line, which in both cases closes with a verb denoting binding in the pluperfect passive ( $\delta \varepsilon \dot{\delta} \varepsilon v \tau o-\dot{\varepsilon} \varphi \tilde{\eta} \pi \tau 0)$.

The pointed reworking of formulaic language invites a comparison of the two scenes. ${ }^{41}$ The parallel cluelessness of Polyphemus and suitors indicates a manifold set of parallels and reversals. Odysseus, once trapped and exposed to the brute force of the Cyclops in the cave, has himself now trapped opponents without weapons in his own home. Unlike Polyphemus, however, he will not let them escape. The literal binding that allowed him to triumph over the imprisoning monster has now become the metaphorical fastening of the fate of those imprisoned. The suitors, cast in Odysseus' previous role, are not unlike Odysseus in that they have entered into some-

39 For a survey of the different approaches to formulaic diction and meaning, see Edwards 1988, 24-42. Most recently, see Bakker 2013, 157-169.

40 In addition to $O d$. 9.442, see $O d .2 .122 ; 7.39,299 ; 11.62 ; 22.32$. See also Il. 16.789 and 9.537 (where, however, it occurs in a different metrical position).

41 Cf. Bakker 2013, 71-72. 
This chapter was published by De Gruyter in the book "Gaze, Vision, and Visuality in Ancient Greek Literature" edited by A. Kampakoglou et al. , 2018. https://www.degruyter.com/view/product/495335

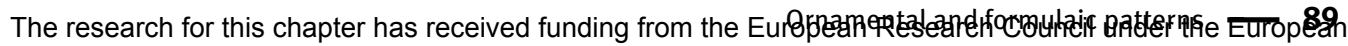
Union's Seventh Framework Programme (FP/2007-2013)/ERC Grant Agreement no. 312321 (AncNar).

body's home in order to take his food supplies. At the same time, their alignment with Polyphemus through the verbal echo of his cluelessness is highly apt. Not only do the suitors share with him the fate of being duped by Odysseus, but like Polyphemus they are accused of breaching the laws of hospitality.

The juxtaposition of the two scenes, driven by what Bakker calls 'interformularity', allows for multiple readings. ${ }^{42}$ It highlights the reversal of Odysseus' fate: mostly a victim and barely managing to protect his life against various aggressors, he has now himself become the aggressor. The reverberation unites such diverse opponents as the monstrous Polyphemus and hybrid aristocrats. No matter whom Odysseus confronts, he is able to pull a trick and outwit his adversary. At the same time, the parallels between the scenes also trigger discomforting questions. Is Odysseus all that different from Polyphemus? ${ }^{43}$ Like the Cyclops, he kills defenceless opponents. The comparison of Polyphemus with a lion, quoted above, echoes uncannily in a simile describing Odysseus after the slaughter of the suitors: 'spattered over with gore and battle filth, like a lion who has been feeding on an ox of the fields, and goes off covered with blood, all his chest and his flanks on either side bloody, a terrible thing to look in the face' (Od. 22.402-405). Odysseus devours the suitors only metaphorically, but nonetheless the evocation of the Cyclops is disquieting. Besides casting a critical light on the manner in which Odysseus slaughters the suitors, it may also challenge his legitimisation. Did Odysseus not commit a similar crime as the suitors when he invaded the cave of the Cyclops in order to steal his cattle?

For my purposes, it is crucial that such far-reaching questions are triggered by the pointed repetition of formulaic diction. This fact yields a thought-provoking parallel to vase-painting: in both cases, repetition endows a formal element with semantic weight. There are of course differences: formulae always denote something; the ornamental can be non-figurative. While exactly the same formula gets repeated in Homer, it may be controversial what qualifies as a pictorial pattern. These differences are due to the different representational systems, language being a semiotic system, painting a perceptual mode of presentation. ${ }^{44}$ If one acknowledges this difference, it appears possible to compare patterns that structure the pictorial plain and formulaic diction as two formal elements defined by repetition. As we have seen, pointed repetition makes both contribute to the meaning of the representation. Just as the triangle

42 Bakker 2013.

43 Cf. Bakker 2013, 53-73, along with Grethlein 2017a, 213-227 for such an interpretation; cf. Grethlein 2017b, which probes the Achillean foil that contributes to the ambiguity of Odysseus' comportment in the execution of the suitors.

44 Even theoreticians like Nelson Goodman (cf. Goodman 1968), who try to grasp pictorial representation as a semiotic system, have to allow for crucial differences. Syntactic and semantic 'density', as well as the greater number of design properties with representational relevance, make the denotation of pictorial symbol systems much more complex than the signification of the notational symbol systems of language. 
pattern on the Eleusis amphora reinforces the juxtaposition of the three figurative friezes, the reworking of formulaic material has Odysseus' escape from the cave and the murder of the suitors shed light on each other. In both cases, the repetition of formal elements generates meaning through comparison.

The same factors seem to regulate the semantic force that formal elements in picture and narrative can have. Not every repetition of a pictorial pattern or formulaic phrase is semantically charged. Just think of the formulaic verse about when 'the young Dawn appeared again with her rosy fingers', which occurs again and again in the Odyssey, or regard the ornamental depiction of vegetation on the Eleusis amphora. In order to grade the semantic significance of formulaic diction, Egbert Bakker proposes an 'interformularity scale': 'the more restricted an expression, the more specific the context in which it is uttered, and the higher the point at which it can be placed on the scale'. ${ }^{45}$ Both points singled out by Bakker equally apply to pictorial patterns: the more a form is used, the less significant it is. It would, for example, make little sense to consider the repetition of straight lines on the Eleusis amphora. Even the triangle is a rather common form, but its significance gains force from the contextual parallels at different levels: in the three figurative friezes it is legs that form triangles. The similar motifs of the three pictures also make it easy to follow up the ornamental parallel: violent confrontations and, in two pictures more specifically, the encounter of man vs. monster.

Pictures and narratives differ in their modes of representation, which have been compared in a long-standing paragone. This difference notwithstanding, the semantic quality of the ornamental in vase-painting is paralleled by the use of formulaic diction in Homeric epic. In both cases, the repetition of formal elements prompts the comparison of scenes, thereby recasting their meaning. Juxtaposed with other scenes, be it the chase of Perseus or the slaughter of the suitors, the blinding of Polyphemus appears in a new light. The juxtaposition also raises larger questions, including, for example, that of heroic comportment. Not every repetition of patterns and diction has such semantic repercussions, however. The capacity to generate meaning depends on how pointed the repetition is.

\section{The ornamental in context}

As a final step, I would like to ponder the extent to which the ornamental is shaped by a specific cultural context (introducing a theme to which Richard Neer returns in his chapter in this volume). As proposed by Bonne and developed further here, the ornamental appears as a transhistorical category. It defines a salient aspect of the logic

45 Bakker 2013, 159. 
This chapter was published by De Gruyter in the book "Gaze, Vision, and Visuality in Ancient Greek Literature" edited by A. Kampakoglou et al. , 2018. https://www.degruyter.com/view/product/495335

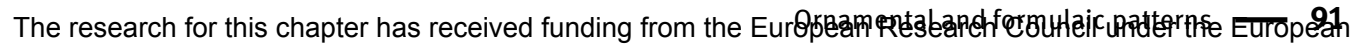
Union's Seventh Framework Programme (FP/2007-2013)/ERC Grant Agreement no. 312321 (AncNar).

of pictures in general. Any picture represents through a medium of which we remain aware when we see in it the represented object. Wollheim finds it impossible to pinpoint what it is that triggers the process of 'seeing-in', but he has no doubts about its phenomenological character. ${ }^{46}$ Across epochs and cultures, beholders, while seeing the object represented in pictures, simultaneously take in the patterns in the pictorial plain.

Something similar can be said about repetition and literature. In Jakobson's famous formulation, poeticity is premised on 'the projection of the principle of equivalence from the axis of selection to the axis of combination' ${ }^{47}$ The principle of equivalence normally governs the selection of one word over another. In literary texts, however, it also governs the combination of words. Words are, for instance, put together because of their equivalence in sound and thereby yield sequences that are rhythmic, alliterative etc. These formal repetitions create equations and are thereby semantically active. A rhyme for example lets us compare the rhyming words and their sentences with each other, as the formal equivalence makes us expect a semantic correspondence.

Jakobson's definition of poeticity is by no means confined to poetry; it also applies to prose texts. In poetic texts, though, poeticity tends to be particularly high. This highlights the gradual nature of poeticity. My test case, Homeric epic, drives home that the density of formal repetitions is also culturally conditioned. The formulaic diction that endows Homer with such a high degree of poeticity in the terms of Jakobson is, as comparative evidence shows, an oral feature. Poeticity may be a transhistorical category of literary texts, and yet its degree and specific form is defined by such cultural factors as orality. Genre, which is key to poeticity, is itself a strongly cultural category.

What about vase-painting? Not only the Eleusis amphora, but Greek vases in general, if in various degrees and ways, are strongly ornamental. Mackay envisages the iconic 'traditional referentiality' as an oral feature. Whether or not this is convincing - after all, schemata seem to be crucial to our perception of pictures in general $^{48}$ - the ornamental quality of Greek vase-painting is better explained along different lines. While paralleling the semantic significance of formulaic diction, the ornamentality of vase-painting has different roots. Here I will touch on the specific medium of pictorial representation and its peculiar spatial logic.

It is important to keep in mind that the carriers of the pictures discussed here is not a neutral ground, but variously shaped vessels which are used for storing, drinking, mixing etc. In adorning vessels, which have various functions independent of the

46 Wollheim 1987, 46.

47 Jakobson 1990 (first published in 1956).

48 E.g. Gombrich 1960. 
This chapter was published by De Gruyter in the book "Gaze, Vision, and Visuality in Ancient Greek Literature" edited by A. Kampakoglou et al. , 2018. https://www.degruyter.com/view/product/495335

The research for thi\$2 9 hapter h Union's Seventh Framework Programme (FP/2007-2013)/ERC Grant Agreement no. 312321 (AncNar).

pictures, vase-painting is decorative. ${ }^{49}$ The decorative character of vase-painting is most conspicuous on Late Geometric vases whose ornaments seem to follow the form of the vessel. ${ }^{50}$ It is still felt though in later vase-painting. There seems to be an amor pleni that prevents the painter from leaving too much empty space. A strong sense of symmetry is also felt in much vase-painting of later periods. The function of decorating a vessel clearly fosters the ornamental quality of vase-painting, as patterns are highly appropriate to the idea of decoration.

A second point that adds force to the ornamental dimension of vase-painting is its specific spatial logic, which Nikolaus Dietrich has subjected to a piercing analysis. Stones, trees and walls, Dietrich shows, are used to depict settings, but do not yield a full-blown pictorial space: ${ }^{51}$

Although places can play an important role in a picture, they are without impact on the spatiality of the image. Places in Attic vase-painting lack spatial quality: their relevance is confined to characterising actions and figures (which, however, can be crucial to the understanding of the image).

As much as Greek vase-painters were interested in mimetic depictions, they showed little interest in making the pictorial field a window into a specific spatial setting.

Let me suggest that both points are linked to each other. The insignificance of represented space, I think, is rooted in the decorative character of the painting. The more present the carrier is with its function, the less it lends itself to becoming a transparent window. The decorative character of vase-painting conflicts with the idea of a pictorial carrier that disappears behind its representation. Instead of being embedded in a represented space, figures on vases interact directly with the space of the vase. The Eleusis amphora is a case in point. Polyphemus is propped against one of the handles which frame the blinding scene on the left and right. In the same vein, we find such objects as shields leaning against the pictorial frame on numerous vases, for example, on the famous Exekias amphora showing Ajax and Achilles playing dice (Fig. 3.5). Other vases show objects hanging from the top as if the rim of the vessel were part of the picture (e.g. Fig. 3.6). ${ }^{52}$ In all these cases, the carrier is somehow present for the represented object. The presence of the vessel that comes to the fore

49 This very general characterisation of the decorative is developed in the context of Greek architecture in Hölscher's chapter in this volume.

50 Martens 1992, 67-75.

51 Dietrich 2010, 98 (my translation): 'Doch auch wenn Orte gelegentlich eine wichtige Rolle in einem Bild einnehmen können, haben sie keinerlei Auswirkungen auf die Räumlichkeit des Bildes. Die Orte in der attischen Vasenmalerei haben keinerlei räumliche Qualität: Damit liegt ihre Bedeutung bloß mehr in der (freilich manchmal für das Verständnis des Bildes entscheidenden) Charakterisierung von Handlungen und Figuren.'

52 For discussion, see Dietrich 2010, 115-116. On the dependence of figural decoration on the form of the ceramic carrier, see also Kéi’s chapter in this volume. 
This chapter was published by De Gruyter in the book "Gaze, Vision, and Visuality in Ancient Greek Literature" edited by A. Kampakoglou et al. , 2018. https://www.degruyter.com/view/product/495335

The research for this chapter has received funding from the Eur8pram Union's Seventh Framework Programme (FP/2007-2013)/ERC Grant Agreement no. 312321 (AncNar).

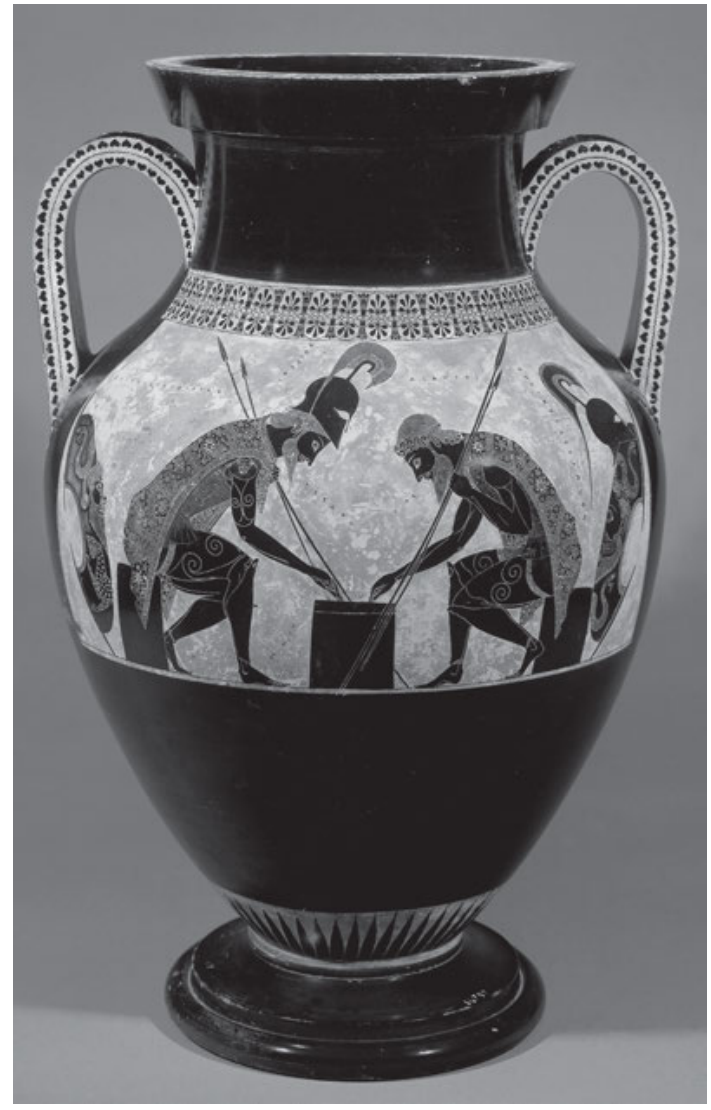

Fig. 3.5: Attic black-figure amphora signed by Exekias, showing Achilles and Ajax playing dice, c. $540 \mathrm{BC}$. Vatican, Musei Vaticani.

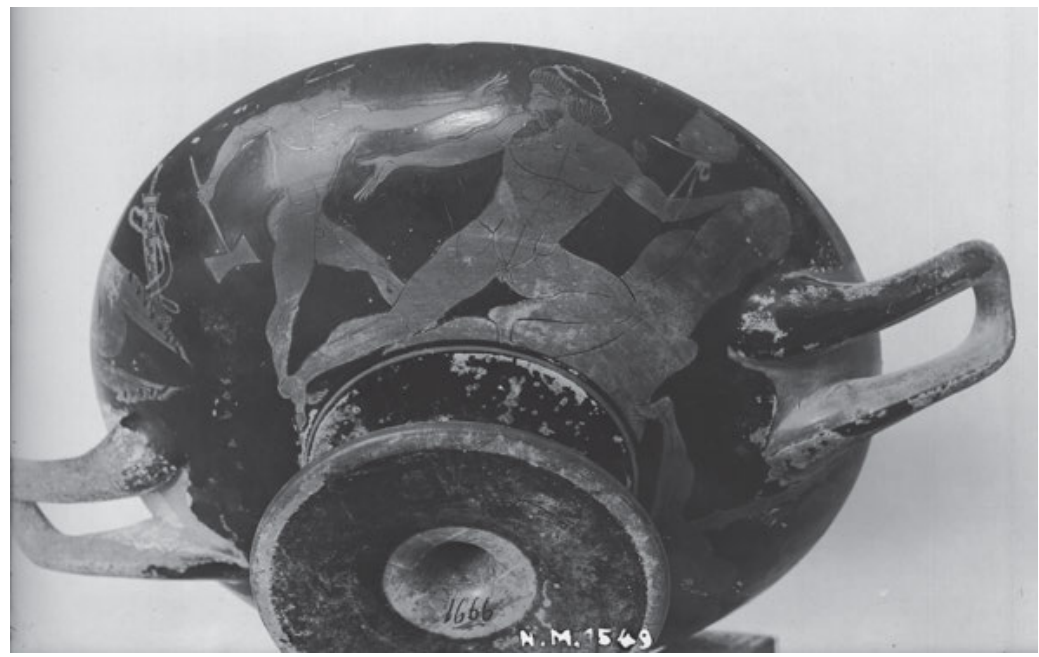

Fig. 3.6: Attic red-figure kylix associated with Douris, c. 525-475 BC. Athens, National Archaeological Museum. 
This chapter was published by De Gruyter in the book "Gaze, Vision, and Visuality in Ancient Greek Literature" edited by A. Kampakoglou et al. , 2018. https://www.degruyter.com/view/product/495335

The research for this 9 thapter h handeccereetalpipding from the European Research Council under the European Union's Seventh Framework Programme (FP/2007-2013)/ERC Grant Agreement no. 312321 (AncNar).

in such depictions ties in with a prominent role of the ornamental which refers to the representing medium.

Any picture, no matter the medium, no matter the epoch, structures the space of its carrier in some way. The more patterns this structuring features, the stronger the picture's ornamental dimension becomes. The ornamentality of Greek vase-painting is noteworthy. Ornaments are pervasive whether inside or outside the pictorial representation. Figurative compositions often reveal strong symmetries. The strong ornamental dimension of vase-painting is an expression of a mode of pictorial representation in which the carrier is highly present. Accordingly, ancient vase-painters did not strive to represent pictorial space, but had their figures interact directly with the pictorial field. The ornamental is a category of pictures in general, but as the example of Greek vase-painting shows, it gains its specific appearance from distinct conventions of representation. Far from invariable, the ornamental is shaped by cultures of picturing the world.

\section{Bibliography}

Andreae, B. and Flashar, H. (1977) 'Strukturäquivalenzen zwischen den homerischen Epen und der frühgriechischen Vasenkunst', Poetica 9: 217-265.

Arend, W. (1933) Die typischen Scenen bei Homer. Berlin.

Bakker, E. J. (2013) The Meaning of Meat and the Structure of the Odyssey. Cambridge.

Becker, A. S. (1990) 'The shield of Achilles and the poetics of Homeric description', American Journal of Philology 111(2): 139-153.

Becker, A. S. (1995) The Shield of Achilles and the Poetics of Ekphrasis. Lanham.

Beyer, V. and Spies, C. (eds.) (2012) Ornament. Motiv - Modus - Bild. Munich.

Bonne, J.-C. (1996) 'Formes et fonctions de l’ornemental dans l'art médiéval (VIle-XIle siècle): le modèle insulaire', in L'image: fonction et usage des images dans l'Occident medieval. Actes du 6e International Workshop on Medieval Societies, Centre Ettore Majorana (Erice, Sicile, 17-23 octobre 1992), ed. J. Baschet. Paris: 207-249.

Bonne, J.-C. (1997) 'De l'ornement à l'ornementalité: la mosaïque absidiale de San Clemente de Rome', in Le rôle de l'ornement dans la peinture murale du Moyen Âge: Actes du colloque international tenu à Saint-Lizier, du 1er au 4 juin 1995, ed. J. Ottaway. Poitiers: 103-119.

Brüderlin, M. (1994) Die Einheit in der Differenz. Die Bedeutung des Ornaments für die abstrakte Kunst des 20. Jahrhunderts; von Philipp Otto Runge bis Frank Stella. Wuppertal.

Dietrich, N. (2010) Figur ohne Raum? Bäume und Felsen in der attischen Vasenmalerei des 6. und 5. Jahrhunderts v. Chr. Berlin.

Edwards, M. W. (1986) 'Homer and oral tradition: The formula, part l', Oral Tradition 1(2): 171-230.

Edwards, M. W. (1988) 'Homer and oral tradition: The formula, part II', Oral Tradition 3(1-2): 11-60. Edwards, M. W. (1992) 'Homer and oral tradition: The type-scene', Oral Tradition 7(2): 284-330. Foley, J. M. (1991) Immanent Art: From Structure to Meaning in Traditional Oral Epic. Bloomington. Frontisi-Ducroux, F. (1995) Du masque au visage: aspects de l'identité en Grèce ancienne. Paris. Glaser, K. (2002) Die Funktion des Ornamentalen. Kommunikationstheoretische Überlegungen zum Ornament als Zeitform. Schliengen.

Gombrich, E. H. (1960) Art and Illusion: A Study in the Psychology of Pictorial Representation. London. 
This chapter was published by De Gruyter in the book "Gaze, Vision, and Visuality in Ancient Greek Literature" edited by A. Kampakoglou et al. , 2018. https://www.degruyter.com/view/product/495335

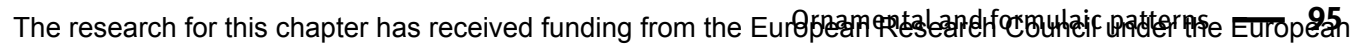
Union's Seventh Framework Programme (FP/2007-2013)/ERC Grant Agreement no. 312321 (AncNar).

Goodman, N. (1968) Languages of Art: An Approach to a Theory of Symbols. Indianapolis.

Grethlein, J. (2015) 'Vision and reflexivity in the Odyssey and early vase-painting', Word \& Image 31: 197-212.

Grethlein, J. (2016) 'Sight and reflexivity: Theorising vision in Greek vase-painting', in Sight and the Ancient Senses, ed. M. J. Squire. London: 85-106.

Grethlein, J. (2017a) Die Odyssee. Homer und die Kunst des Erzählens. Munich.

Grethlein, J. (2017b) '“The best of the Achaeans"? Odysseus and Achilles in the Odyssey', in The Making of the Homeric Epics: Language, Performance, Criticism, eds. C. Tsagalis and A. Tsakmakis. Berlin: 123-146.

Grethlein, J. (2017c) Aesthetic Experience and Classical Antiquity: The Significance of Form in Narratives and Pictures. Cambridge.

Hampe, R. (1936) Frühe griechische Sagenbilder in Boeotien. Athens.

Hampe, R. (1952) Die Gleichnisse Homers und die Bildkunst seiner Zeit. Tübingen.

Haug, A. (2015) Bild und Ornament im frühen Athen. Regensburg.

Hetzer, T. (1987) Das Ornamentale und die Gestalt. Stuttgart.

Himmelmann, N. (1968) Über einige gegenständliche Bedeutungsmöglichkeiten des frühgriechischen Ornaments. Mainz.

Howe, T. P. (1954) 'The origin and function of the Gorgon-head', American Journal of Archaeology 58(3): 209-221.

Hurwit, J. M. (1977) 'Image and frame in Greek art', American Journal of Archaeology 81(1): 1-30.

Hurwit, J. M. (1992) 'A note on ornament, nature, and boundary in early Greek art', Bulletin Antieke Beschavung 67: 63-72.

Jacobsthal, P. (1927) Ornamente griechischer Vasen. Berlin.

Jakobson, R. (1990 [1956]) 'Two aspects of language and two types of aphasic disturbances', in On Language, eds. L. R. Waugh and M. Monville-Burston. Cambridge, MA: 115-133.

Lewis, T. S. W. (1981) 'Homeric epic and the Greek vase', in The Greek Vase: Papers Based on Lectures Presented to a Symposium Held at Hudson Valley Community College at Troy, New York in April of 1979, ed. S. L. Hyatt. Latham, NY: 81-102.

Luhmann, N. (1995) Die Kunst der Gesellschaft. Frankfurt am Main.

Mack, R. (2002) 'Facing down Medusa (an aetiology of the gaze)', Art History 25(5): 571-604.

Mackay, E. A. (1993) 'The oral shaping of culture', Scholia 2: 97-116.

Mackay, E. A. (1995) 'Narrative tradition in early Greek oral poetry and vase-painting', Oral Tradition 10: 282-303.

Mackay, E. A. (1996) 'Time and timelessness in the traditions of early Greek oral poetry and archaic vase-painting', in Voice into Text: Orality and Literacy in Ancient Greece, ed. I. Worthington. Leiden: 43-58.

Mackay, E. A. (2002) 'The evocation of emotional response in early Greek poetry and painting', in Epea and Grammata: Oral and Written Communication in Ancient Greece, eds. I. Worthington and J. M. Foley. Leiden: 55-69.

Marconi, C. (2017) 'The frames of Greek painted pottery', in The Frame in Classical Art: A Cultural History, eds. V. J. Platt and M. J. Squire. Cambridge: 117-153.

Martens, D. (1992) Une esthétique de la transgression: le vase grec de la fin de l'époque géométrique au début de l'époque classique. Brussels.

Morris, I. (1993) 'Poetics of power: The interpretation of ritual action in Archaic Greece', in Cultural Poetics in Archaic Greece: Cult, Performance, Politics, eds. C. Dougherty and L. Kurke. Cambridge: $15-45$.

Morris, S. P. (1984) The Black and White Style: Athens and Aigina in the Orientalizing Period. New Haven.

Mylonas, G. E. (1957) Ho prōtoattikos amphoreus tēs Eleusinos. Athens. 
This chapter was published by De Gruyter in the book "Gaze, Vision, and Visuality in Ancient Greek Literature" edited by A. Kampakoglou et al. , 2018. https://www.degruyter.com/view/product/495335

The research for this 96 apter h Union's Seventh Framework Programme (FP/2007-2013)/ERC Grant Agreement no. 312321 (AncNar).

Neer, R. T. (2002) Style and Politics in Athenian Vase-Painting: The Craft of Democracy, ca. 530-460 B.C.E. Cambridge.

Neer, R. T. (2010) The Emergence of the Classical Style in Greek Sculpture. Chicago.

Notopoulos, J. A. (1957) 'Homer and Geometric art: A comparative study in the formulaic technique of composition', Athena 61: 65-93.

Osborne, R. (1988) 'Death revisited, death revised: The death of the artist in Archaic and Classical Greece', Art History 11(1): 1-16.

Osborne, R. (1998) Archaic and Classical Greek Art. Oxford.

Pächt, O. (1933) ‘Gestaltungsprinzipien der westlichen Malerei des 15. Jahrhunderts', Kunstwissenschaftliche Forschungen 2: 75-100.

Parry, M. (1971) The Making of Homeric Verse: The Collected Papers of Milman Parry. Oxford.

Platt, V. J. and Squire, M. J. (2017) 'Framing the visual in Greek and Roman antiquity: An introduction', in The Frame in Classical Art: A Cultural History, eds. V. J. Platt and M. J. Squire. Cambridge: 1-99.

Roque, G. (2010/2011) 'Ornement et modernisme’, Perspective 1: 18-20.

Squire, M. J. (2009) Image and Text in Graeco-Roman Antiquity. Cambridge.

Squire, M. J. (2013) 'Ekphrasis at the forge and the forging of ekphrasis: The "Shield of Achilles" in Graeco-Roman word and image', Word \& Image 29(2): 157-191.

Vernant, J.-P. (1990) Figures, idoles, masques. Paris.

Whitley, J. (1994) 'Protoattic pottery: A contextual approach', in Classical Greece: Ancient Histories and Modern Archaeologies, ed. I. Morris. Cambridge: 51-70.

Whitman, C. H. (1958) Homer and the Heroic Tradition. Cambridge, MA.

Winkler-Horacek, L. (2015) Monster in der frühgriechischen Kunst. Die Überwindung des Unfassbaren. Berlin.

Wollheim, R. (1980) Art and its Objects, 2nd edn. Cambridge.

Wollheim, R. (1987) Painting as an Art. London.

\section{Image credits}

Fig. 3.1: (C) Museum of Fine Arts, Boston.

Fig. 3.2: (C DAI Athen, DAI-Neg. D-DAl-Ath-Eleusis 546 (Photograph: Eva-Maria Czakó).

Fig. 3.3: (C) DAI Athen, DAI-Neg. D-DAl-Ath-Eleusis 547 (Photograph: Eva-Maria Czakó).

Fig. 3.4: (C) DAI Athen, DAI-Neg. D-DAI-Ath-Eleusis 545 (Photograph: Eva-Maria Czakó).

Fig. 3.5: (C) bpk/Scala.

Fig. 3.6: @ DAI Athen, DAI-Neg. D-DAI-ATH-NM1549. 